\title{
Analisis Efektivitas Social Media Dan Faktor Yang Mempengaruhi Keputusan Pembelian Es Krim Wall's Magnum Berdasarkan Karakteristik Pengeluaran (Studi Kasus Mahasiswa Program Strata 1 lpb)
}

\author{
Syifa Ratna Pujasari \\ Alumni Departemen Manajemen, Fakultas Ekonomi dan Manajemen \\ Institut Pertanian Bogor \\ Muhammad Syamsun \\ Departemen Manajemen, Fakultas Ekonomi dan Manajemen \\ Institut Pertanian Bogor \\ R. Dikky Indrawan \\ Departemen Manajemen, Fakultas Ekonomi dan Manajemen \\ Institut Pertanian Bogor \\ Email: rdikky@yahoo.com
}

\begin{abstract}
The objectives of this study are (1) to find the effectiveness of social media used by Wall's Magnum ice cream based on the characteristics of the expenditure and (2) to analyze the factors that influence consumer purchasing decisions of Wall's Magnum ice cream based on characteristics of the expenditure. The research framework is using the Consumer Decision Model which analyze by regression analysis and consumer purchasing decisions model which analyze by descriptive analysis. The correlations between both models were analyzed by Canonical Correlation using of MINITAB 14, SPSS 16.00, Ms Excel and STATISTICA 8. The path analysis by CDM model for respondent with $\leq R p 800,000$ expenditure and for respondent with $>R p 800.000$ were showing effectiveness of information about Wall's Magnum sent through social media. However, the path analysis showed that CDM model for respondent with $\leq R p 800,000$ expenditure is more effective rather than the CDM model and for respondent with $>R p$ 800.000. The results of canonical correlation analysis showed the most influencing factors on purchase decisions for respondent with the expense $\leq R p 800,000$ are brand and place of purchase, mean while the most influencing factors for respondent with the expenditure $>R p 800,000$ are previous experience and packaging.

Keywords: Effectiveness of Social Media, CDM, Purchase Decision, Characteristics of Expenditure
\end{abstract}

\section{Pendahuluan}

Zaman globalisasi saat ini telah membawa dampak persaingan yang semakin ketat terhadap industri es krim di Indonesia. Industri es krim di Indonesia saat ini sedang giat-giatnya bersaing di dalam mempertahankan serta memperebutkan pangsa pasar 
yang luas bagi dunia perekonomian di Indonesia. Salah satu perusahaan es krim terkenal di Indonesia yaitu Es Krim Wall's yang merupakan salah satu merek produk es krim dari PT. Unilever, Tbk. Menghadapi persaingan yang hebat di Industri es krim, Wall's menyiasatinya dengan melakukan peremajaan produk pada salah satu es krimnya yaitu Wall's Magnum. Wall's Magnum adalah es krim yang membawa kelezatan cokelat belgia yang melapisi es krim vanilla di dalamnya, kini hadir dengan tiga varian rasa baru (Classic, Almond, dan Chocolate Truffle).

Munculnya varian rasa terbaru es krim Magnum menjadikan es krim ini begitu fenomenal, semua orang dibuat penasaran, membicarakan serta membeli es krim ini. Hal ini berdampak pada stok es krim Magnum yang habis dimana-mana. Fenomena dan fakta Magnum begitu sulit didapat dipasaran, atau dapat disebut seolah-olah habis dan laku dipasaran merupakan salah satu strategi promosi perusahaan yang unik serta bertujuan menciptakan pola marketing yang sedikit berbeda. Kelangkaan tersebut akan menyebabkan orang semakin mencari dan penasaran untuk mencicipinya. Di zaman yang serba terhubung dengan internet serta social media yang semakin marak (facebook, twitter, friendster, kaskus, dII), menyebarnya fenomena ini melalui word of mouth yang di fasilitasi oleh social media adalah sangat mudah sehingga menimbulkan efek menular yang sangat besar. Semakin banyaknya orang yang menulis status updates di dalam social media mereka, memberikan dampak yang sangat signifikan terhadap penjualan es krim Magnum.

Fenomena Magnum melalui word of mouth yang di fasilitasi social media, menyebabkan efek yang sangat besar. Informasi yang disebarkan akan sangat cepat beredar ke tiap pembaca dan tiap pembaca membawa berita dari dunia maya ini ke dunia nyata. Maka akan tercipta pemikiran bahwa produk Magnum ini memang benarbenar enak dan patut untuk dicoba.

Sebuah artikel menarik di Majalah Marketing Mix edisi 11 April-10 Mei 2007 yang ditulis oleh Harry Puspito, Direktur Pengelola MRI, Marketing Research Indonesia, tentang kalahnya pengaruh iklan ATL (TV, radio dan cetak) dibanding medium Word of Mouth (WOM), patut dicermati secara serius bagi pengiklan. Hasil dari penelitian tersebut didapat bukan iklan televisi yang menjadi sumber informasi terbaik dan memberi pengaruh terbesar dalam pengambilan keputusan, melainkan melalui Word of Mouth.

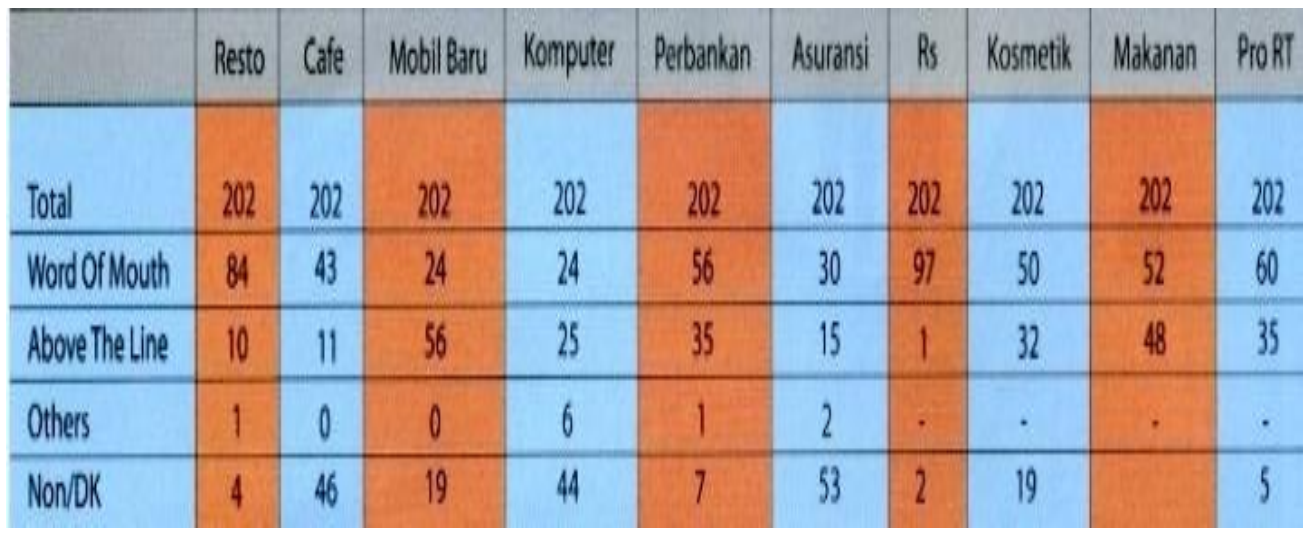

Gambar 1. Kalahnya pengaruh iklan ATL dibanding medium WOM

(Puspito, 2007) 
Fakta tersebut didukung dengan hasil riset Nielsen Media Reseach, April 2009, rekomendasi orang yang dikenal (teman atau saudara) masih menduduki posisi pertama sebagai sumber informasi iklan terpercaya. Namun, opini konsumen di dunia maya menduduki posisi kedua yang paling menentukan konsumen untuk membeli. Posisi ketiga dan selanjutnya baru diisi oleh berbagai jenis iklan

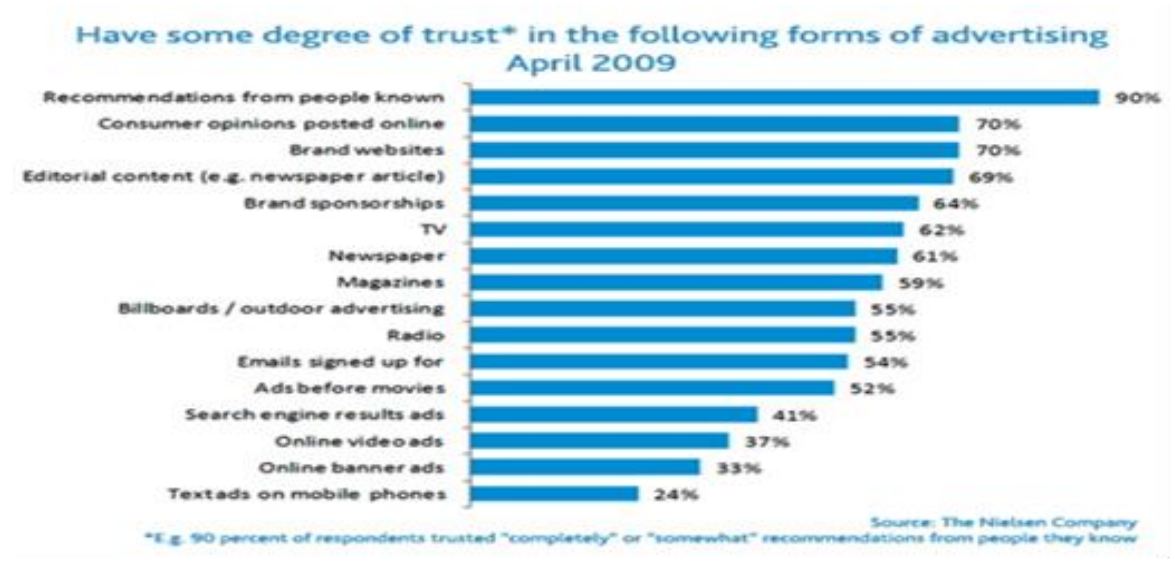

Gambar 2. Sumber informasi iklan terpercaya (Nielsen Media Research, 2009)

Segmentasi pasar yang dituju es krim Wall's Magnum adalah Masyarakat kelas menengah atas. Hal ini berpengaruh terhadap karakteristik pengeluaran konsumen yang dituju dalam melakukan keputusan pembelian untuk mengkonsumsi makanan non-pokok seperti es krim Wall's Magnum. Oleh karena itu, penting mengetahui hubungan karakteristik pengeluaran konsumen terhadap efektivitas social media sehingga akan tercipta keputusan pembelian untuk membeli es krim Wall's Magnum.

Penelitian ini dimaksudkan untuk mengetahui efektivitas social media dan faktor yang mempengaruhi keputusan pembelian es krim wall's Magnum berdasarkan karakteristik pengeluaran. Perumusan masalah dalam penelitian ini, akan dirumuskan sebagai berikut :

1. Bagaimanakah efektivitas social media es krim Wall's Magnum dalam mengkomunikasikan informasinya kepada konsumen berdasarkan karakteristik pengeluaran?

2. Faktor apa saja yang mempengaruhi keputusan pembelian konsumen es krim Wall's Magnum berdasarkan karakteristik pengeluaran?

Berdasarkan rumusan masalah tersebut, maka tujuan dari penelitian ini adalah :

1. Mengetahui efektivitas social media es krim Wall's Magnum dalam mengkomunikasikan informasinya kepada konsumen berdasarkan karakteristik pengeluaran.

2. Mengetahui faktor-faktor yang mempengaruhi keputusan pembelian konsumen es krim Wall's Magnum berdasarkan karakteristik pengeluaran.

\section{Metode Penelitian}

Semakin tingginya tingkat persaingan di Industri es krim saat ini, menuntut es krim Wall's Magnum untuk terus memperkuat posisi produk tersebut di pasar Indonesia. 
Mengingat es krim Wall's Magnum baru saja mengeluarkan permeajaan produk, perlu diadakan pengenalan produk baru tersebut di benak konsumen saat ini. Pengenalan produk dapat dilakukan melalui proses komunikasi pemasaran melalui social media. Penelitian ini menggunakan dua alat analisis yang membantu dalam proses pengolahan data, yaitu Consumer Decision Model digunakan untuk mengetahui efektifitas social media dalam keputusan pembeliaan Es Krim Wall's Magnum dan analisis canonical correlation untuk menganalisis faktor-faktor yang menjadi pertimbangan dalam keputusan pembelian Es Krim Wall's Magnum oleh konsumen. Gambar 3 memperlihatkan kerangka pemikiran dalam penelitian ini.

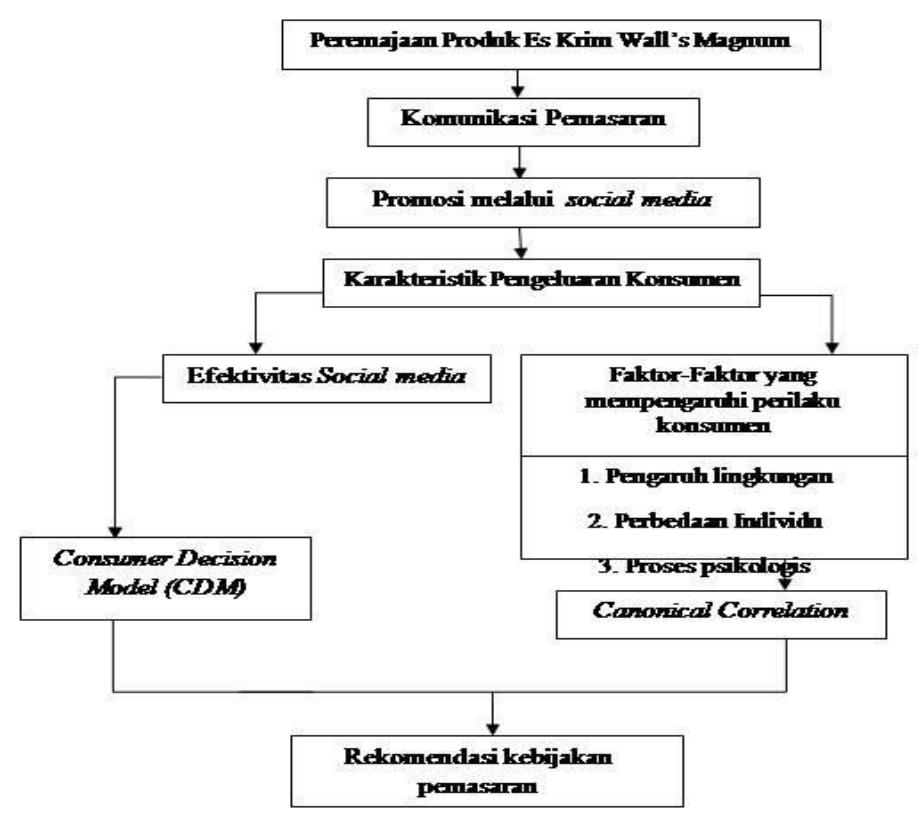

Gambar 3. Kerangka Pemikiran Konseptual

Lokasi Penelitian ini dilakukan di kampus Institut Pertanian Bogor (IPB) yang berlokasi di Dramaga, Bogor, Jawa Barat dari bulan Februari sampai dengan Maret 2011. Jenis data yang digunakan adalah data primer dan data sekunder. Data primer diperoleh melalui diperoleh dari hasil penyebaran kuesioner kepada responden, yaitu Mahasiswa Strata 1 (S1) IPB. Data sekunder diperoleh melalui : studi literatur, internet, dan hasil penelitian terdahulu yang berkaitan dan masih relevan untuk digunakan.

Populasi dari penelitian ini adalah Mahasiswa Strata 1 (S1) IPB yang mengkonsumsi atau pernah mendengar informasi di social media mengenai Es Krim Wall's Magnum dan pengguna social media. Teknik pengambilan contoh yang digunakan adalah secara nonprobability sampling Metode yang digunakan adalah metode convenience sampling. Penentuan jumlah contoh dari populasi dalam penelitian ini dilakukan berdasarkan metode Slovin dengan asumsi bahwa populasi berdistribusi normal (Umar, 2005) berikut :

$$
\mathrm{n}=\frac{\mathrm{N}}{1+\mathrm{Ne}^{2}}
$$


Berdasarkan informasi yang diperoleh dari AJMP IPB Dramaga Bogor, jumlah mahasiswa aktif S1 di IPB Dramaga Bogor berjumlah 15547 orang per Oktober 2010. Dengan nilai e sebesar 10\%, diperoleh nilai 99,99 dibulatkan menjadi 100 mahasiswa untuk dijadikan responden.

Penelitian ini menggunakan uji kuesioner seperti uji validitas dan uji reliabilitas. Pengolahan dan analisis data dilakukan dengan bantuan program Statistical Product and Service Solution (SPSS) versi 16 dan Microsoft Excel 2007 terhadap 30 responden.

\section{Hasil Penelitian}

Es krim Wall's Magnum adalah produk es krim yang diproduksi oleh PT. Unilever, Tbk dan dijual sebagai produk dari Wall's di beberapa negara. Es krim Wall's Magnum terdiri atas Es krim vanilla dibalut Coklat Belgia. Wall's Magnum, salah satu merek es krim Unilever terkemuka yang membawa kelezatan cokelat yang sesungguhnya untuk pasar es krim dewasa.

Pada tahun 2010, Wall's melakukan peremajaan produk Magnum dengan meluncurkan tiga varian rasa baru yaitu Wall's Magnum Classic, Wall's Magnum Almond, dan Wall's Magnum Chocolate Truffle, ketiga produk tersebut merupakan produk unggulan dari Wall's. Es krim Wall's Magnum tercipta dengan platform baru yang memberikan pengalaman berkelas, yaitu pleasure indulgence atau kenikmatan cita rasa tinggi yang dapat terasa pada gigitan pertama lapisan coklat Belgia lalu menyatu dengan es krim vanilla yang lembut membuat varian baru Wall's Magnum ini terasa sangat berbeda.

\section{III.1. Karakteristik Responden}

Responden yang terlibat dalam penelitian ini sebanyak 100 orang mahasiswa dan informasi karakteristik responden diperoleh berdasarkan kuesioner yang disebarkan kepada 100 mahasiswa strata 1 IPB yang memenuhi kriteria yaitu pernah melihat informasi mengenai es krim Wall's Magnum di social media.

Tabel 1. Karakteristik responden

\begin{tabular}{|c|c|c|}
\hline \multicolumn{2}{|c|}{ Karakteristik Responden } & \multirow{2}{*}{$\frac{\text { Persentase (\%) }}{80}$} \\
\hline Jenis Kelamin & Perempuan & \\
\hline & Laki-Laki & 20 \\
\hline \multirow[t]{3}{*}{ Variasi Rasa } & Classic & 46 \\
\hline & Almond & 40 \\
\hline & Chocolate Truffle & 14 \\
\hline \multirow[t]{2}{*}{ Pengeluaran } & $\leq R p 800.000$ & 66 \\
\hline & $>R p 800.000$ & 34 \\
\hline \multirow[t]{3}{*}{ Pembelian Es Krim } & Tidak jadi beli & 38 \\
\hline & $\begin{array}{l}\text { Ganti merek es krim, tapi masih } \\
\text { Wall's }\end{array}$ & 56 \\
\hline & Ganti merek dan produsen lain & 6 \\
\hline \multirow[t]{3}{*}{ Tempat Pembelian } & Minimarket & 41 \\
\hline & Supermaket & 53 \\
\hline & Warung & 6 \\
\hline Meng-Update status mengenai es krim & $1-3$ Kali & 93 \\
\hline \multirow[t]{2}{*}{ Wall's Magnum } & $4-6$ Kali & 5 \\
\hline & $7-10 \mathrm{Kali}$ & 3 \\
\hline \multirow[t]{2}{*}{ Akun social media yang dimiliki } & Facebook & 27,16 \\
\hline & Twitter & 23,1 \\
\hline
\end{tabular}




$\begin{array}{clc} & \text { Friendster } & 19,29 \\ & \text { Kaskus } & 5,08 \\ & \text { Blog } & 16,23 \\ & \text { Tumblr } & 4,82 \\ & \text { Plurk } & 1,78 \\ & \text { Lainnya } & 2,54 \\ \text { Setelah membeli maka meng-update } & \text { Ya } & 55 \\ \text { status } & \text { Tidak } & 45 \\ \text { Tidak membeli maka meng-update status } & \text { Yidak } & 32 \\ \text { Terdorong membeli dan mencari es krim } & \text { Ya } & 68 \\ \text { Wall's Magnum } & \text { Tidak } & 76 \\ \text { Teman selebritis di akun social media } & 1-15 \text { orang } & 24 \\ & 16-30 \text { orang } & 84 \\ \text { Teman selebritis meng-update status } & \text { 31-45 orang } & 13 \\ \text { Tabel 3. Hasil analisis regresi sederhana dan } & \text { regresi linier berganda } & 2 \\ & \text { Tidak Pernah } & 1 \\ & & 22 \\ & & 78\end{array}$

Tabulasi silang antar variabel karakteristik dilakukan untuk melihat keterkaitan antar karakteristik responden berdasarkan besar pengeluarannya.

Tabel 2. Tabulasi silang karakteristik responden dengan besar pengeluarannya

\begin{tabular}{clcc}
\hline Karakteristik Responden & & $\leq$ Rp 800.000 (\%) & $>$ Rp 800.000 (\%) \\
\hline Membeli Wall's Magnum & $2-6$ Kali & 52 & 11 \\
& $7-12$ Kali & 14 & 17 \\
Melihat status updates/informasi tentang & $13-20$ Kali & 0 & 6 \\
es krim Wall's Magnum di social media & $7-6$ Kali & 50 & 15 \\
& $12-17$ Kali & 15 & 12 \\
Memberi Komentar tentang es krim & $1-5$ Kali & 1 & 7 \\
Wall's Magnum di social media & $6-10 \mathrm{Kali}$ & 64 & 21 \\
& $11-15 \mathrm{Kali}$ & 2 & 11 \\
\hline
\end{tabular}

\section{III.2. Hasil Analisis Consumer Decision Model (CDM)}

Pada penelitian ini dibandingkan antara dua kelompok yaitu kelompok pengeluaran $\leq$ Rp 800.000 dan kelompok pengeluaran > Rp 800.000 untuk mengetahui perbedaan dalam proses pengambilan keputusan pembelian es krim Wall's Magnum dan menilai efektivitas social media es krim Wall's Magnum.

Tabel 3, menunjukan hasil regresi sederhana yang dilakukan pada kedua kelompok tersebut yaitu kelompok pengeluaran $\leq \mathrm{Rp} 800.000$ dan kelompok pengeluaran $>\mathrm{Rp}$ 800.000 menjelaskan bahwa seluruh regresi sederhana adalah signifikan. Hal ini menunjukan bahwa seluruh variabel memiliki hubungan yang signifikan karena pada regresi sederhana menunjukan bahwa $\mathrm{H}_{01}$ ditolak, yang berarti kedua persamaan tersebut memiliki pengaruh variabel independen terhadap variabel dependen adalah signifikan karena memiliki $p$-value lebih kecil dari nilai alpha yang digunakan yaitu 0,05 dan $t_{\text {hitung }}$ lebih besar daripada nilai $t_{\text {tabel }}(1,987)$. Hasil regresi sederhana yang telah dilakukan mengintrepretasikan bahwa antara variabel dependen dan variabel independen pada es krim Wall's Magnum memiliki pengaruh langsung antara lain pengaruh langsung variabel informasi di social media terhadap variabel pengenalan merek, pengaruh langsung informasi di social media tehadap kepercayaan konsumen, 
pengaruh langsung informasi di social media terhadap sikap konsumen, pengaruh langsung pengenalan merek terhadap kepercayaan konsumen, pengaruh langsung pengenalan merek terhadap sikap konsumen, pengaruh langsung kepercayaan konsumen terhadap niat beli, pengaruh langsung sikap konsumen terhadap niat beli, dan pengaruh langsung niat beli terhadap pembelian nyata. Sehingga dapat dikatakan bahwa variabel independen pada es krim Wall's Magnum memiliki pengaruh yang signifikan terhadap variabel dependen produk Wall's Magnum.

Hasil analisis regresi linier berganda signifikan apabila memiliki $p$-value lebih kecil dari nilai alpha yaitu 0,05 dan $F_{\text {hitung }}$ lebih besar daripada nilai $F_{\text {tabel }}(3,101)$ maka $\mathrm{H}_{02}\left(\mathrm{X}_{1}\right.$ dan $\left.X_{2}\right)$ ditolak. Artinya kedua variabel independen $\left(X_{1}\right.$ dan $\left.X_{2}\right)$ memiliki kontribusi yang signifikan secara serempak terhadap variabel dependen yang dirasakan untuk merek Wall's Magnum. Selanjutnya jika memiliki taraf nyata lebih kecil dari nilai alpha yang digunakan yaitu sebesar 0,05 dan nilai $t_{\text {hitung }}$ lebih besar daripada nilai $t_{\text {tabel }}(1,988)$, maka $\mathrm{H}_{03}\left(\mathrm{X}_{1}\right)$ dan $\mathrm{H}_{04}\left(\mathrm{X}_{2}\right)$ ditolak sehingga pengaruh masing-masing variabel independen $\left(X_{1}\right.$ dan $\left.X_{2}\right)$ secara parsial terhadap variabel dependen produk Wall's Magnum adalah signifikan. Terdapat perbedaan pada hasil regresi linier berganda yang dilakukan pada kedua kelompok tersebut. Untuk kelompok pengeluaran $\leq \mathrm{Rp} 800.000$, hasil regresi linier berganda yang dilakukan menunjukan bahwa kedua variabel independen memiliki kontribusi yang signifikan secara serempak maupun parsial terhadap variabel dependen yang dirasakan untuk merek Wall's Magnum. Hasil regresi linier berganda yang telah dilakukan mengintrepretasikan bahwa antara variabel dependen dan variabel independen memiliki pengaruh yang diperoleh dari variabel pada es krim Wall's Magnum antara lain pengaruh variabel informasi di social media dan pengenalan merek terhadap kepercayaan konsumen, pengaruh variabel informasi di social media dan pengenalan merek terhadap sikap konsumen, dan pengaruh variabel kepercayaan konsumen dan sikap konsumen terhadap niat beli. Sehingga dapat dikatakan bahwa kedua variabel independen pada es krim Wall's Magnum memiliki pengaruh yang signifikan baik secara serempak maupun secara parsial terhadap variabel dependen produk Wall's Magnum.

Sedangkan berdasarkan hasil regresi linier berganda pada kelompok pengeluaran $>$ Rp 800.000 terdapat hasil yang tidak signifikan yaitu kesemua regresi linier berganda yang dilakukan pada kedua variabel independen Wall's Magnum terhadap variabel dependen Wall's Magnum. Variabel tersebut antara lain, regresi linier berganda yang pertama antara variabel informasi di social media dan pengenalan merek terhadap kepercayaan konsumen terhadap es krim Wall's Magnum, diperoleh hasil bahwa variabel informasi di social media tidak signifikan sehingga informasi yang dilihat melalui social media tidak cukup membangun kepercayaan konsumen terhadap es krim Wall's Magnum, sedangkan variabel pengenalan merek es krim Wall's Magnum memiliki kontribusi yang signifikan terhadap kepercayaan konsumen pada es krim Wall's Magnum sehingga pengenalan merek yang dilakukan es krim Wall's Magnum mampu meningkatkan kepercayaan konsumen terhadap es krim Wall's Magnum. Dapat disimpulkan bahwa pengaruh pengenalan merek dan informasi di social media berpengaruh signifikan secara serempak, namun tidak berpengaruh signifikan apabila secara parsial terhadap kepercayaan konsumen es krim Wall's Magnum yang memiliki pengeluaran $>\mathrm{Rp} 800.000$. Hasil regresi linier berganda yang kedua adalah pengaruh 
variabel informasi di social media dan pengenalan merek terhadap sikap konsumen terhadap es krim Wall's Magnum, diperoleh hasil bahwa variabel pengenalan merek tidak signifikan sehingga pengenalan merek mengenai es krim Wall's Magnum tidak cukup membangun sikap konsumen terhadap es krim Wall's Magnum, sedangkan variabel informasi di social media memiliki kontribusi yang signifikan terhadap sikap konsumen pada es krim Wall's Magnum sehingga informasi di social media mengenai es krim Wall's Magnum mampu meningkatkan sikap konsumen terhadap es krim Wall's Magnum. Dapat disimpulkan bahwa pengaruh pengenalan merek dan informasi di social media berpengaruh signifikan secara serempak, namun tidak berpengaruh signifikan apabila secara parsial terhadap sikap konsumen es krim Wall's Magnum yang memiliki pengeluaran $>\mathrm{Rp} 800.000$. Hasil regresi linier yang ketiga antara variabel kepercayaan konsumen terhadap es krim Wall's Magnum tidak memiliki kontribusi yang signifikan terhadap niat beli yang dirasakan konsumen es krim Wall's Magnum, sehingga kepercayaan konsumen yang dirasakan pada produk es krim Wall's Magnum tidak dapat meningkatkan niat beli konsumen terhadap es krim Wall's Magnum. Sedangkan variabel sikap konsumen memiliki kontribusi yang signifikan terhadap niat beli yang dirasakan konsumen terhadap es krim Wall's Magnum, sehingga sikap konsumen terhadap es krim Wall's Magnum dapat meningkatkan niat beli yang dirasakan konsumen terhadap es krim Wall's Magnum. Dapat disimpulkan bahwa pengaruh kepercayaan konsumen dan sikap konsumen berpengaruh signifikan secara serempak, namun tidak berpengaruh signifikan apabila secara parsial terhadap niat beli yang dirasakan konsumen terhadap es krim Wall's Magnum yang memiliki pengeluaran $>\operatorname{Rp} 800.000$.

\section{III.3. Hasil Pengaruh Variabel Antara}

Untuk membuktikan ada tidaknya variabel antara, digunakan alat bantu koefisien determinasi $\left(R^{2}\right)$. Suatu variabel akan dinyatakan sebagai variabel antara jika koefisien determinasi dari suatu variabel terhadap variabel antara tersebut lebih besar daripada nilai koefisien determinasi dari variabel termaksud ke variabel akhir.

Tabel 3. Hasil analisis regresi pengaruh variabel antara

\begin{tabular}{|c|c|c|c|c|}
\hline \multirow{2}{*}{ Variabel } & \multicolumn{2}{|c|}{ Pengeluaran $\leq \mathrm{Rp} 800.000$} & \multicolumn{2}{|c|}{ Pengeluaran > Rp 800.000} \\
\hline & Koefisien Determinasi $\left(\mathrm{R}^{2}\right)$ & Arti & Koefisien Determinasi $\left(\mathrm{R}^{2}\right)$ & Arti \\
\hline $\mathrm{F}-\mathrm{C}-\mathrm{I}$ & $\begin{array}{l}R^{2} \mathrm{FI}=0,184 \\
R^{2} \mathrm{FC}=0,363 \\
R^{2} \mathrm{Cl}=0,727 \\
R^{2} \mathrm{FI}<\mathrm{R}^{2} \mathrm{FC}<\quad \mathrm{R}^{2} \mathrm{Cl}\end{array}$ & $\begin{array}{l}\text { C Merupakan } \\
\text { Variabel Antara }\end{array}$ & $\begin{array}{l}R^{2} \mathrm{FI}=0,294 \\
R^{2} \mathrm{FC}=0,527 \\
\mathrm{R}^{2} \mathrm{Cl}=0,499 \\
\mathrm{R}^{2} \mathrm{FI}<\mathrm{R}^{2} \mathrm{Cl}<\mathrm{R}^{2} \mathrm{FC}\end{array}$ & $\begin{array}{l}\text { C Bukan } \\
\text { Merupakan } \\
\text { Variabel Antara }\end{array}$ \\
\hline$F-A-I$ & $\begin{array}{l}R^{2} F I=0,184 \\
R^{2} F A=0,557 \\
R^{2} A I=0,811 \\
R^{2} F I<R^{2} F A<R^{2} A I\end{array}$ & $\begin{array}{l}\text { A Merupakan } \\
\text { Variabel Antara }\end{array}$ & $\begin{array}{l}R^{2} F I=0,294 \\
R^{2} F A=0,652 \\
R^{2} A I=0,754 \\
R^{2} F I<R^{2} F A<R^{2} A I\end{array}$ & $\begin{array}{l}\text { A Merupakan } \\
\text { Variabel Antara }\end{array}$ \\
\hline$F-B-C$ & $\begin{array}{l}R^{2} F C=0,363 \\
R^{2} F B=0,562 \\
R^{2} B C=0,967 \\
R^{2} F C<R^{2} F B<R^{2} B C\end{array}$ & $\begin{array}{l}\text { B Merupakan } \\
\text { Variabel Antara }\end{array}$ & $\begin{array}{l}R^{2} F C=0,527 \\
R^{2} F B=0,628 \\
R^{2} B C=0,735 \\
R^{2} F C<R^{2} F B<R^{2} B C\end{array}$ & $\begin{array}{l}\text { B Merupakan } \\
\text { Variabel Antara }\end{array}$ \\
\hline$F-B-A$ & $\begin{array}{l}R^{2} F A=0,557 \\
R^{2} F B=0,562 \\
R^{2} B A=0,847 \\
R^{2} F A<R^{2} F B<R^{2} B A\end{array}$ & $\begin{array}{l}\text { B Merupakan } \\
\text { Variabel Antara }\end{array}$ & $\begin{array}{l}R^{2} F A=0,652 \\
R^{2} F B=0,628 \\
R^{2} B A=0,592 \\
R^{2} B A<R^{2} F B<R^{2} F A\end{array}$ & $\begin{array}{l}\text { B Bukan } \\
\text { Merupakan } \\
\text { Variabel Antara }\end{array}$ \\
\hline$C-I-P$ & $R^{2} C P=0,720$ & I Merupakan & $R^{2} C P=0,563$ & I Bukan \\
\hline
\end{tabular}




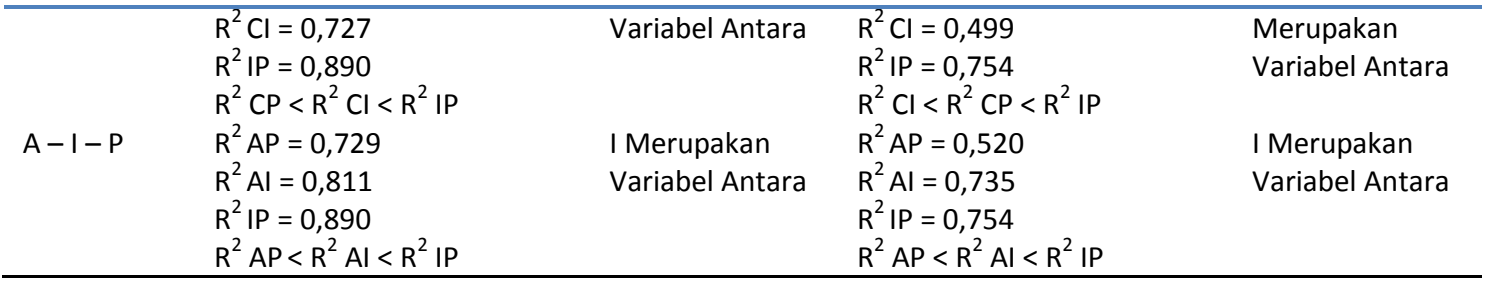

Berdasarkan hasil pada Tabel 4. Menujukan bahwa pada kelompok pengeluaran $\leq$ Rp 800.000 variabel yang bertindak sebagai variabel antara dalam penelitian mengenai efektivitas social media es krim Wall's Magnum ini adalah variabel kepercayaan konsumen (C), variabel sikap konsumen (A), variabel pengenalan merek (B) dan variabel niat beli (I). Hal ini menujukan berarti variabel kepercayaan konsumen (C) memperkuat pengaruh antara variabel informasi di social media $(\mathrm{F})$ terhadap variabel niat beli (I), variabel sikap konsumen (A) memperkuat pengaruh antara variabel informasi di social media (F) terhadap variabel niat beli (I), variabel pengenalan merek (B) memperkuat pengaruh antara variabel informasi di social media (F) terhadap variabel kepercayaan konsumen (C), variabel pengenalan merek (B) memperkuat pengaruh antara variabel informasi di social media (F) terhadap variabel sikap konsumen (A), variabel niat beli (I) memperkuat pengaruh antara variabel sikap konsumen $(A)$ terhadap variabel pembelian nyata $(P)$, dan variabel niat beli (I) memperkuat pengaruh antara variabel kepercayaan konsumen $(C)$ terhadap variabel pembelian nyata $(\mathrm{P})$.

Sedangkan pada kelompok pengeluaran $>$ Rp 800.000 diperoleh hasil yaitu variabel yang bertindak sebagai variabel antara dalam penelitian mengenai efektivitas social media es krim Wall's Magnum ini adalah variabel sikap konsumen (A), variabel pengenalan merek (B) dan variabel niat beli (I), hal ini menujukan berarti variabel kepercayaan konsumen (C) tidak memperkuat pengaruh antara variabel informasi di social media (F) terhadap variabel niat beli (I), variabel sikap konsumen (A) memperkuat pengaruh antara variabel informasi di social media (F) terhadap variabel niat beli (I), variabel pengenalan merek (B) memperkuat pengaruh antara variabel informasi di social media (F) terhadap variabel kepercayaan konsumen (C), variabel pengenalan merek (B) tidak memperkuat pengaruh antara variabel informasi di social media $(F)$ terhadap variabel sikap konsumen $(A)$, variabel niat beli (I) memperkuat pengaruh antara variabel sikap konsumen $(A)$ terhadap variabel pembelian nyata $(P)$, dan variabel niat beli (I) tidak memperkuat pengaruh antara variabel kepercayaan konsumen $(C)$ terhadap variabel pembelian nyata $(P)$.

\section{III.4. Hasil Analisis Consumer Decision Model (CDM)}

Informasi di social media mengenai es krim Wall's Magnum berpengaruh terhadap variabel-variabel yang diukur pada Consumer Decision Model sampai dengan variabel pembelian nyata seperti yang terlihat pada Gambar 4 dan Gambar 5. Sehingga dapat dikatakan bahwa informasi mengenai es krim Wall's Magnum di social media tersebut mampu mengkomunikasikan informasi dengan efektif kepada konsumen. Gambar 4 yang merupakan kelompok pengeluaran $\leq \mathrm{Rp} 800.000$ menunjukan hasil analisis regresi linier bahwa seluruh variabel mempunyai hubungan yang signifikan. 
Variabel yang bertindak sebagai variabel antara dalam penelitian mengenai efektivitas social media es krim Wall's Magnum, yaitu: variabel pengenalan merek (B), variabel kepercayaan konsumen (C), variabel sikap konsumen (A) dan niat beli (I). Berdasarkan hasil analisis regresi dan pengaruh antara variabel untuk produk es krim Wall's Magnum, maka diketahui, informasi di social media (F) mengenai es krim Wall's Magnum efektif sampai mempengaruhi pembelian nyata $(P)$ yang dilakukan konsumen es krim Wall's Magnum karena setiap model yang ada pada CDM memiliki pengaruh dari variabel informasi di social media hingga variabel pembelian nyata (P). Sehingga dapat dikatakan bahwa informasi di social media (F) mengenai es krim Wall's Magnum mampu mengkomunikasikan informasi dengan efektif kepada konsumen hingga timbul pembelian nyata (P). Informasi di social media (F) menjadi lebih efektif dalam mempengaruhi pembelian nyata melalui keempat variabel perantara, yaitu: variabel pengenalan merek (B), variabel kepercayaan konsumen (C), variabel sikap konsumen (A) dan niat beli (I). Dengan demikian, enam alternatif untuk mencapai pembelian nyata (P) yang ada pada CDM dapat digunakan semuanya untuk kelompok pengeluaran $\leq \mathrm{Rp} 800.000$ konsumen produk es krim Wall's Magnum.

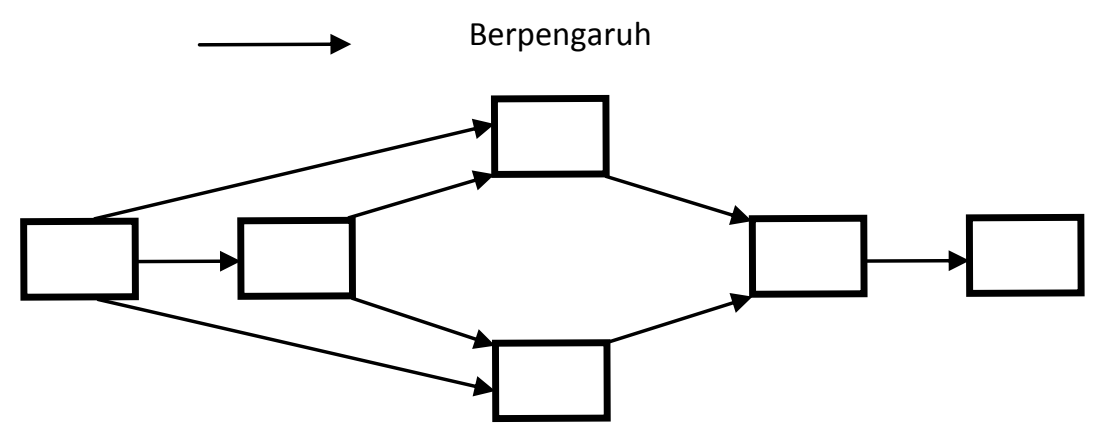

Gambar 4. Hasil Consumer Decision Model (CDM) es krim Wall's Magnum kelompok pengeluaran $\leq$ Rp 800.000 (Data Primer, 2011)

Gambar 5, yang merupakan kelompok pengeluaran > Rp 800.000 menunjukan hasil bahwa variabel kepercayaan konsumen (C) bukan variabel antara sehingga variabel informasi di social media (F) tidak mampu membangun kepercayaan konsumen (C) terhadap es krim Wall's Magnum untuk meningkatkan niat beli (I) konsumen es krim Wall's Magnum. Adapun variabel pengenalan merek (B) bukan variabel antara sehingga informasi di social media (F) tidak mampu membangun pengenalan merek (B) es Krim Wall's Magnum untuk meningkatkan sikap konsumen (A) terhadap es krim Wall's Magnum. Variabel niat beli (I) bukan variabel antara sehingga informasi di social media (F) tidak mampu membangun kepercayaan konsumen (C) terhadap es krim Wall's Magnum sehingga tidak dapat meningkatkan niat beli (I) konsumen es krim Wall's Magnum apalagi meningkatkan pembelian nyata $(P)$ konsumen untuk membeli es krim Wall's Magnum. Dapat dikatakan bahwa informasi di social media mengenai es krim Wall's Magnum mampu mengkomunikasikan informasi dengan efektif kepada 
konsumen hingga timbul pembelian nyata apabila melewati informasi di social media (F) mengenai es krim Wall's Magnum yang mampu membangun sikap konsumen (A) terhadap es krim Wall's Magnum sehingga dapat meningkatkan niat beli (I) dan meningkatkan pembelian nyata $(P)$ konsumen untuk membeli es krim Wall's Magnum.

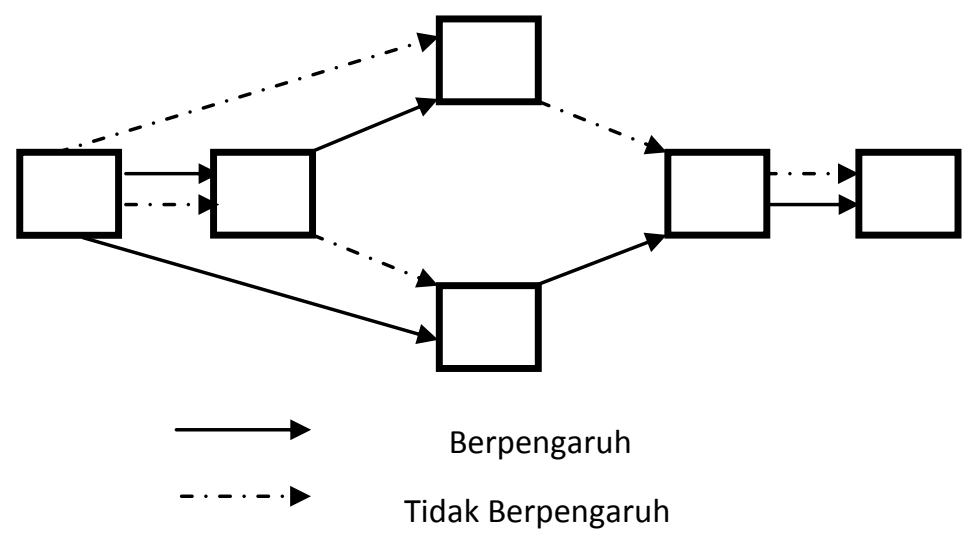

Gambar 5. Hasil Consumer Decision Model (CDM) es krim Wall's Magnum kelompok pengeluaran $>$ Rp 800.000 (Data Primer, 2011)

\section{III.5. Analisis Korelasi Kanonikal}

Hasil analisis korelasi kanonik yang dilakukan dengan menggunakan bantuan program STATISTICA 8 menghasilkan fungsi kanonik pada kelompok konsumen pengeluaran $\leq \mathrm{Rp} 800.000$ yang memiliki nilai korelasi maksimum dan menghasilkan persamaan sebagai berikut:

$\mathbf{X}^{*}=0,113072 X_{1}-0,132180 X_{2}-0,046626 X_{3}-0,492437 X_{4}-0,421566 X_{5}-0,463643 X_{6}-$ $0,493078 X_{7}-0,089636 X_{8}+0,370634 X_{9}+0,377858 X_{10}+0,651352 X_{11}+$ $0,057150 X_{12}+0,107831 X_{13}-0,641177 X_{14}-0,054604 X_{15}+0,107963 X_{16}+$ $0,089447 X_{17}+0,158532 X_{18}+0,319127 X_{19}+0,233031 X_{20}$

$\mathbf{Y}^{*}=-0,393978 Y_{1}+1,260100 Y_{2}-0,552562 Y_{3}-0,034292 Y_{4}-0,485490 Y_{5}$

Nilai korelasi yang dihasilkan dari persamaan diatas adalah sebesar 0,749. Untuk dapat melihat seberapa besar pembelian nyata $(Y)$ dapat dijelaskan oleh faktor-faktor yang mempengaruhi perilaku konsumen $(X)$ digunakan nilai $R^{2}$. Berdasarkan hasil pengolahan, nilai $R^{2}$ yang didapat adalah sebesar 0,561 . Artinya adalah variasi gugus peubah pembelian nyata konsumen yang dapat dijelaskan oleh gugus peubah faktorfaktor yang mempengaruhi perilaku konsumen adalah sebesar 56,1 persen, sisanya sebesar 43,9 persen dijelaskan oleh faktor diluar model yang digunakan.

Sedangkan fungsi kanonik pada kelompok pengeluaran $>$ Rp 800.000 yang memiliki nilai korelasi maksimum dan menghasilkan persamaan sebagai berikut:

$$
\begin{aligned}
\mathbf{X}^{*}= & -0,137335 X_{1}+0,324293 X_{2}-0,271196 X_{3}+0,437233 X_{4}-0,049275 X_{5}-0,440663 X_{6}- \\
& 0,181933 X_{7}+0,588531 X_{8}+0,327185 X_{9}+0,068934 X_{10}+0,383764 X_{11}- \\
& 0,020331 X_{12}+0,110383 X_{13}-0,322228 X_{14}+0,342047 X_{15}+0,105031 X_{16}- \\
& 0,380329 X_{17}-0,235452 X_{18}+0,047017 X_{19}-0,684475 X_{20} \\
Y^{*}= & -0,637424 Y_{1}+0,234514 Y_{2}-0,368978 Y_{3}+0,917646 Y_{4}-0,429467 Y_{5}
\end{aligned}
$$


Nilai korelasi yang dihasilkan dari persamaan diatas adalah sebesar 0,925. Untuk dapat melihat seberapa besar pembelian nyata $(Y)$ dapat dijelaskan oleh faktor-faktor yang mempengaruhi perilaku konsumen $(X)$ digunakan nilai $\mathrm{R}^{2}$. Berdasarkan hasil pengolahan, nilai $R^{2}$ yang didapat adalah sebesar 0,856 . Artinya adalah variasi gugus peubah pembelian nyata konsumen yang dapat dijelaskan oleh gugus peubah faktorfaktor yang mempengaruhi perilaku konsumen adalah sebesar 85,6 persen, sisanya sebesar 14,4 persen dijelaskan oleh faktor diluar model yang digunakan.

Besarnya bobot kanonik untuk masing-masing peubah asal yang membentuk fungsi kanonik pada kedua kelompok pengeluaran konsumen dapat dilihat pada Tabel 5. Faktor-faktor perilaku konsumen (X) yang memiliki bobot kanonik cukup besar (diatas $0,5)$ dianggap mampu menjelaskan keragaman pembelian nyata untuk membeli es krim Wall's Magnum yang terjadi dan sebaliknya. Berdasarkan interpretasi terhadap bobot kanonik diperoleh bahwa faktor yang paling berpengaruh terhadap pembelian nyata konsumen untuk membeli es krim Wall's Magnum pada kelompok pengeluaran $\leq$ $\mathrm{Rp} 800.000$ adalah peubah merek $\left(\mathrm{X}_{11}\right)$ dan tempat pembelian $\left(\mathrm{X}_{14}\right)$ yang memiliki bobot sebesar 0,651 dan -0,641. Hal ini terjadi karena informasi di social media mengenai es krim Wall's Magnum mampu menampilkan karakter merek magnum yang kuat dan menginformasikan mengenai tempat pembelian yang menyediakan es krim Wall's Magnum.

Tabel 4. Bobot kanonik dan beban kanonik

\begin{tabular}{|c|c|c|c|c|}
\hline \multirow{2}{*}{ Variabel } & \multicolumn{2}{|c|}{ Bobot Kanonik } & \multicolumn{2}{|c|}{ Beban Kanonik } \\
\hline & $\leq \mathrm{Rp} 800.000$ & $>\operatorname{Rp} 800.000$ & $\leq \mathrm{Rp} 800.000$ & $>\operatorname{Rp} 800.000$ \\
\hline \multicolumn{5}{|l|}{ Peubah Bebas } \\
\hline $\mathrm{X} 1$ & 0,113072 & $-0,137335$ & 0,168020 & $-0,051473$ \\
\hline $\mathrm{X} 2$ & $-0,132180$ & 0,324293 & 0,146926 & 0,360816 \\
\hline X3 & $-0,046626$ & $-0,271196$ & $-0,205172$ & $-0,479859$ \\
\hline$X 4$ & $-0,492437$ & 0,437233 & $-0,004386$ & 0,046572 \\
\hline X5 & $-0,421566$ & $-0,049275$ & $-0,099736$ & $-0,234259$ \\
\hline$x 6$ & $-0,463643$ & $-0,440663$ & $-0,147170$ & 0,089591 \\
\hline $\mathrm{X7}$ & $-0,493078$ & $-0,181933$ & $-0,179791$ & 0,156056 \\
\hline$x 8$ & $-0,089636$ & 0,588531 & 0,082875 & 0,419959 \\
\hline X9 & 0,370634 & 0,327185 & 0,218500 & 0,110274 \\
\hline $\mathrm{X} 10$ & 0,377858 & 0,068934 & 0,198919 & $-0,136320$ \\
\hline $\mathrm{X} 11$ & 0,651352 & 0,383764 & 0,402362 & 0,064492 \\
\hline $\mathrm{X} 12$ & 0,057150 & $-0,020331$ & 0,073923 & 0,052347 \\
\hline $\mathrm{X} 13$ & 0,107831 & 0,110383 & 0,186099 & 0,208101 \\
\hline $\mathrm{X} 14$ & $-0,641177$ & $-0,322228$ & $-0,301744$ & $-0,447394$ \\
\hline $\mathrm{X} 15$ & $-0,054604$ & 0,342047 & 0,270565 & 0,091382 \\
\hline $\mathrm{X} 16$ & 0,107963 & 0,105031 & 0,141623 & 0,015688 \\
\hline $\mathrm{X} 17$ & 0,089447 & $-0,380329$ & 0,222993 & 0,029943 \\
\hline $\mathrm{X} 18$ & 0,158532 & $-0,235452$ & 0,244137 & 0,003821 \\
\hline $\mathrm{X} 19$ & 0,319127 & 0,047017 & 0,243071 & $-0,127891$ \\
\hline $\mathrm{X} 20$ & 0,233031 & $-0,684475$ & 0,105007 & $-0,441924$ \\
\hline \multicolumn{5}{|c|}{ Peubah Tak Bebas } \\
\hline Y1 & $-0,393978$ & $-0,637424$ & $-0,316834$ & $-0,692348$ \\
\hline Y2 & 1,260100 & 0,234514 & 0,532107 & $-0,175094$ \\
\hline Y3 & $-0,552562$ & $-0,368978$ & $-0,052283$ & $-0,349459$ \\
\hline Y4 & $-0,034292$ & 0,917646 & $-0,132710$ & 0,481798 \\
\hline Y5 & $-0,485490$ & $-0,429467$ & $-0,352687$ & $-0,066780$ \\
\hline
\end{tabular}


Berdasarkan interpretasi terhadap bobot kanonik diperoleh bahwa faktor yang paling berpengaruh terhadap pembelian nyata konsumen untuk membeli es krim Wall's Magnum pada kelompok pengeluaran $>$ Rp 800.000 adalah peubah pengalaman terdahulu $\left(X_{20}\right)$ dan bentuk kemasan $\left(X_{8}\right)$ yang memiliki nilai bobot sebesar -0,684 dan 0,588 . Hal ini terjadi karena informasi di social media mengenai es krim Wall's Magnum mampu menampilkan bentuk kemasan dan menginformasikan mengenai perbandingan pengalaman terdahulu mengkonsumsi es krim selain Wall's Magnum.

Penelusuran lebih lanjut pada beban kanonik untuk kelompok pengeluaran $\leq \mathrm{Rp}$ 800.000 dan kelompok pengeluaran > Rp 800.000 menunjukkan bahwa tidak ada faktor perilaku konsumen yang paling berpengaruh terhadap pembeliaan nyata konsumen untuk membeli es krim Wall's Magnum karena tidak ada peubah faktor perilaku konsumen $(X)$ yang memiliki nilai beban kanonik diatas 0,5 sehingga semua faktor perilaku konsumen $(X)$ mempengaruhi secara keseluruhan terhadap peubah pembelian nyata (Y).

\section{KESIMPULAN}

Berdasarkan hasil analisis Consumer Decision Model diketahui bahwa informasi yang ingin disampaikan oleh produsen Wall's Magnum melalui social media berpengaruh terhadap variabel yang diukur pada Consumer Decision Model dari variabel informasi di social media (F) sampai dengan variabel pembelian nyata ( $P$ ). Terdapat perbedaan antara kelompok konsumen berpengeluaran $\leq \mathrm{Rp} 800.000$ dan kelompok konsumen berpengeluaran > Rp 800.000 dalam proses pengambilan keputusan pembelian es krim Wall's Magnum dan menilai efektivitas social media es krim Wall's Magnum. Kelompok pengeluaran $\leq \mathrm{Rp} 800.000$, informasi di social media (F) mengenai es krim Wall's Magnum efektif sampai mempengaruhi pembelian nyata $(P)$ yang dilakukan konsumen es krim Wall's Magnum karena setiap model yang ada pada CDM memiliki pengaruh dari variabel informasi di social media (F) hingga variabel pembelian nyata (P). Kelompok pengeluaran > Rp 800.000, informasi di social media (F) mengenai es krim Wall's Magnum mampu mengkomunikasikan informasi dengan efektif kepada konsumen hingga timbul pembelian nyata (P) apabila melewati informasi di social media (F) mengenai es krim Wall's Magnum yang mampu membangun sikap konsumen (A) terhadap es krim Wall's Magnum sehingga dapat meningkatkan niat beli (I) dan meningkatkan pembelian nyata $(P)$ konsumen untuk membeli es krim Wall's Magnum.

Faktor yang paling berpengaruh terhadap pembelian nyata konsumen untuk membeli es krim Wall's Magnum berdasarkan analisis bobot kanonik dan beban kanonik dengan menggunakan analisis korelasi kanonik pada kelompok pengeluaran $\leq$ Rp 800.00 adalah faktor merek dan tempat pembelian. Sedangkan untuk kelompok pengeluaran $>\mathrm{Rp} 800.000$ adalah pengalaman terdahulu dan bentuk kemasan.

\section{DAFTAR PUSTAKA}

Amalia, A. 2009. Analisis Hubungan antara word of mouth positif dan negatif terhadap emosi, sikap, dan purchase intentions bukan konsumen macaroni panggang Bogor. 
Skripsi pada Departemen Manajemen Fakultas Ekonomi dan Manajemen, Institut Pertanian Bogor, Bogor.

Durianto, D, dkk. 2003. Invasi Pasar dengan Iklan yang Efektif: Strategi, Program, dan Teknik Pengukuran. PT. Gramedia Pustaka Utama, Jakarta.

Engel. F. Blackweel, D. Miniard W. 1994. Consumer Behaviour 6th ed, Jilid 1 (terjemahan). Binarupa Aksara, Jakarta.

Hidayat, T. 2008. Adu Strategi di Pasar Es Krim. http://202.59.162.82/swamajalah. [09 Desember 2010].

Jachja, I. F. 2007. Word of Mouth, Kalahkan Pengaruh Iklan ATL. http://virtual.co.id. [09 Desember 2010].

Kotler, P, dan Armstrong, G. 2004. Dasar-Dasar Pemasaran, Edisi Kesembilan, Jilid 1. Indeks, Jakarta.

Kotler, P. 2005 Manajemen Pemasaran Edisi 11 (Terjemahan, Jilid 2). Indeks. Jakarta.

Kuncoro, M. 2003. Metode Riset Untuk Bisnis dan Ekonomi. Penerbit Erlangga, Jakarta.

Lutfhie, N. 2010. Apa Kata Teman di Media Sosial Lebih Penting Ketimbang Iklan. http://virtual.co.id. [3 Maret 2011].

Nielsen Media Research. 2009. Sumber Informasi Iklan Terpercaya: 2009. (April). Nielsen Media Research, Jakarta.

Nugroho, Bhuono Agung. 2005. Strategi Jitu: Memilih Metode Statistik Penelitian dengan SPSS. Penerbit ANDI, Yogyakarta.

Permatasari, S. D. 2010. Analisis Efektivitas Iklan Televisi Deodoran Pria Axe dan Faktor-faktor yang Mempengaruhi Niat Beli Deodoran Khusus Pria pada Konsumen. Skripsi pada Departemen Manajemen Fakultas Ekonomi dan Manajemen, Institut Pertanian Bogor, Bogor.

Puspito, H. 2007. Kalahnya Pengaruh Iklan ATL (TV, radio dan cetak) dibanding Medium Word of Mouth (WOM) Edisi 10 April - 11 Mei 2007. Majalah Marketing Mix.

Thoyibie, L. 2010. Psikologi Social Media. http://komunikasi-indonesia.org. [08 Februari 2011].

Tjiptono, F. 2008. Strategi Pemasaran. Edisi 3. ANDI, Yogyakarta.

Tjiptono, dkk. 2008. Pemasaran Strategik, Edisi 1. CV. Andi Offset. Yogyakarta.

Solaita, N. 2009. Analisis efektivitas word of mouth marketing dalam mempertahankan pasar roti "unyil" Venus Bogor. Skripsi pada Departemen Teknologi Industri Pertanian Fakultas Teknologi Pertanian, Institut Pertanian Bogor, Bogor.

Sumarwan, U. 2003. Perilaku Konsumen. Ghalia Indonesia, Jakarta.

Umar, H. 2005. Metode Penelitian untuk Skripsi dan Tesis Bisnis. PT. Raja Grafindo Persada, Jakarta. 
Unilever, 2010. Kelezatan Cokelat Belgia dalam Setiap Gigitan Wall's Magnum Ice Cream Terbaru. http://www.unilever.co.id. [09 Desember 2010].

Wikipedia, 2010. Pengertian Es Krim. http://id.wikipedia.org. [17 Desember 2010].

Zuraida, L. dan Uswatun. 2001. Analisis Efektivitas Iklan Rinso, Soklin dan Attack dengan Menggunakan Consumer Decision Model (CDM). Usahawan, 4: pp.3. 